\title{
Detection of occult HER2 mRNA-positive tumor cells in the peripheral blood of patients with operable breast cancer: evaluation of their prognostic relevance
}

\author{
Stella Apostolaki - Maria Perraki - Galatea Kallergi - Maria Kafousi · \\ Savvas Papadopoulos - Athanasios Kotsakis - Athanasios Pallis • Nikolaos Xenidis • \\ Lyda Kalmanti · Kostas Kalbakis · Sofia Agelaki • Antonia Kalykaki • \\ Christos Stournaras · Efstathios Stathopoulos • Vassilis Georgoulias • \\ Dimitris Mavroudis
}

Published online: 21 January 2009

(C) Springer Science+Business Media, LLC. 2009

\section{Erratum to: Breast Cancer Res Treat DOI 10.1007/s10549-008-0239-3}

Unfortunately, one of the paragraphs contained some mistakes. Please find the corrected paragraph below.

\section{Nested reverse transcription-polymerase chain reaction (RT-PCR)}

A previously described nested RT-PCR assay for the detection of HER2 mRNA [21] with minor modifications was used [22]. Reverse transcription of RNA was carried out with the Thermoscript RT-PCR system (Invitrogen,

The online version of the original article can be found under doi:10.1007/s10549-008-0239-3.

S. Apostolaki · M. Perraki · V. Georgoulias · D. Mavroudis Laboratory of Tumor Cell Biology, School of Medicine, University of Crete, Heraklion, Crete, Greece

G. Kallergi · C. Stournaras

Department of Biochemistry, School of Medicine,

University of Crete, Heraklion, Crete, Greece

M. Kafousi · E. Stathopoulos

Department of Pathology, University General Hospital

of Heraklion, Heraklion, Crete, Greece

S. Papadopoulos

Department of Pathology, "Ygeia" Hospital, Athens, Greece

A. Kotsakis · A. Pallis · N. Xenidis · L. Kalmanti

K. Kalbakis - S. Agelaki - A. Kalykaki - V. Georgoulias ·

D. Mavroudis $(\square)$

Department of Medical Oncology, University General Hospital of Heraklion, P.O. Box 1352, 71110 Heraklion, Crete, Greece

e-mail: georgsec@med.uoc.gr
Paisley, UK). cDNA was synthesized according to the manufacturer's instructions. Two different PCR reactions, with the respective negative controls, were performed with each sample in order to amplify fragments of HER2 and $\beta$-actin. The sequences of primers used for HER2 (synthesized by Gencet, Paris, France) were as follows: $5^{\prime} \mathrm{TC}$ CTCCTCGCCCTCTTGC3' (sense Her-2-A); 5'GCGGGT CTCCATTGTCTA3' (antisense Her-2-B); 5'AGCCGCGA GCACCCAAGT3' (sense Her-2-C); 5'TTGGTGGGCAGG TAGGTGAGTT3' (antisense Her-2-D). To amplify cDNA, $2 \mu \mathrm{l}$ were subjected to first PCR in $20 \mu \mathrm{l}$ buffer [ $10 \mathrm{mM}$ of HCL, buffer (pH 8.3), $50 \mathrm{mM} \mathrm{KCL}$ and $2.5 \mathrm{mM} \mathrm{MgCl}_{2}$ ] containing $1 \mathrm{mM}$ deoxynucleotide triphosphate, $3 \mu \mathrm{M}$ of primers (Her-2-A and Her-2-B) and 2.5 units platinum Taq DNA polymerase (Invitrogen). For the second round of amplification (nested RT-PCR) a $2 \mu \mathrm{l}$ aliquot of first PCR product was added to the same PCR buffer with $1 \mathrm{mM}$ deoxynucleotide triphosphate, $3 \mu \mathrm{M}$ of primers (Her-2-C and Her-2-D) and 2.5 units platinum Taq DNA polymerase. The nested RT-PCR was performed using a modified touchdown program as previously described [22]. All PCR products were electrophoresed in agarose $2 \%$ gel, stained with ethidium bromide and photographed under UV conditions. In order to determine the sensitivity of the assay, MCF-7, T47D and SKBR3 cells were mixed with normal PBMCs in a cell ratio ranging from 1:10 to $1: 10^{6}$, and total RNA was extracted from these cell dilutions and tested for HER2 mRNA by nested RT-PCR. 